\title{
Effects of temperature and pressure on the transformation rate from air bubbles to air-hydrate crystals in ice sheets
}

\author{
TSUTOMU UCHIDA, \\ Hokkaido National Industrial Research Institule, Sapporo 062, Japan \\ TAKEO HONDOH, \\ Institute of Low Temperature Science, Hokkaido University, Sapporo 060, Japan \\ Shinji MAe, \\ Department of Applied Physics, Hokkaido University, Sapporo 060, Japan \\ Paul Duval, \\ Laboraloire de Glaciologie et Géophysique de l'Environnement, CNRS, 38402 Saint-Martin-d'Hères Cedex, France \\ VOLODYA YA. LIPENKOV \\ Arctic and Antartic Research Institute, St. Petersburg 199226, Russia
}

\begin{abstract}
Experimental investigations on the formation and growth processes of air-hydrate crystals were carried out to determine the transformation process of air bubbles into air-hydrate crystals in deep ice sheets. The microscopic observations revealed that the transformation began at the boundary between a bubble and ice. Faster transformation occurred along the boundary and, subscquently, the transformation progressed towards the center of the bubble at a lower rate. Each transformation rate increased with pressure and also with temperature. The activation energy of the transformation was about $0.52 \mathrm{eV}$ for the primary transformation process and about $0.90 \mathrm{eV}$ for subsequent processes. These results indicate that the rate determining the process of transformation is mainly supplementation of water molecules to the transformation site. An estimation of the transformation period of an air bubble into an air-hydrate crystal in a deep icc shect reveals that it is about onethousandth of the time period of the transition zonc, where both air-hydrates and air bubbles exist.
\end{abstract}

\section{INTRODUCTION}

Air bubbles in polar ice sheets are formed when firn changes into ice. 'The gas composition included in the bubble is essentially the same as that of the atmosphere at the time of pore close-off. Analyses of the gas composition in ice cores then allow us to investigate previous climatic conditions.

However, all air bubbles disappear below several hundreds of meters depth, for example, below $1200 \mathrm{~m}$ depth in the Byrd Station ice core, Antarctica (Gow and others, 1968). Miller (1969) suggested that the airhydrate might exist in bubble-free ice. Gow and Williamson (1975) reported the detailed air-bubble characteristics of Byrd Station ice cores and they discussed the arguments for and against gas-hydrate formation. Air-hydrate inclusions had been discovered in fresh Dye-3 ice cores, Greenland, deeper than about $1100 \mathrm{~m}$ by Shoji and Iangway (1982). Their discovery verified that air-hydrates had maintaincd previous atmospheric gases in deeper parts of the ice sheet.

Air-hydrate is a small and transparent substance, whose diameter is as small as a few hundreds $\mu \mathrm{m}$. The airhydrate crystal is stable under conditions of high pressure and low temperature. Air-hydrate is the crystalline molecular complex formed from the mixturc of water and atmospheric gases. X-ray diffraction studies of airhydrates obtained from the Dyc-3 ice core Hondoh and others, 1990) revealed that their crystal structure was cubic, while the surrounding ice lattice was hexagonal. They also showed that water molecules formed two types of cage: 16-hedral "large cage" and 12-hedral "small cage".

The depth distributions of both air bubbles and airhydrate crystals were studied in detail in the Vostok ice cores (Lipenkov, 1989; Uchida and others, 1994). They revealed that the transformation of air-hydrate crystals from air bubbles progressed gradually with depth. In the Vostok ice, air-hydrate crystals began to form at about $500 \mathrm{~m}$ depth and air bubbles disappeared completely by 
$1250 \mathrm{~m}$. Both air bubbles and air-hydrate crystals co-exist in this depth range, referred to here as the transition zone. This depth range corresponds to about 60000 years (Lorius and others, 1985). The transition zone has been observed in other deep icc cores (Shoji and Langway, 1987; Lipenkov and others, 1989).

As mentioned above, the air-hydrate crystal is the main storage of ancient atmospheric gases in a dccper region of the ice sheets. However, it is not well-known whether the gas compositions are the same between the air-hydrate crystal and the original air bubble. Moreover, the transformation from air bubbles to air-hydrate crystals is one of phase change. One should then cxamine whether the gas compositions in the air-hydrate crystals -are the same as those before their transformation.

The spcctroscopic analysis of the natural air-hydrate crystals (Nakahara and others, 1988) revealed that the crystals mainly included $\mathrm{N}_{2}$ and $\mathrm{O}_{2}$ molecules. It also revealed that the composition ratio of $\mathrm{N}_{2}$ and $\mathrm{O}_{2}$ in the air-hydrate, $\mathrm{N}_{2} / \mathrm{O}_{2}$, was about 1.7 , which was markedly smaller than the ratio 4 in the present-day air. X-ray diffraction studies of air-hydrate crystals (Hondoh and others, 1990) revealed that the occupancy of air molecules in cach cage was about 0.8. Optical microscopic observation of the transformation process of an airhydrate crystal from an air bubble (Cchida and others, 1992) revealed that air-hydrate crystals observed in ice sheets were formed by pressurization of air bubbles. An air-hydrate crystal is, therefore, the main storage of ancient atmospheric gases in a deep ice core but its composition may change with a phase change.

In the present study, we carried out experimental studies on the transformation process at various pressures and tempcratures to find the elementary process of the transformation from an air bubble to an air-hydrate crystal. 'The results show that the transformation rate is determined mainly by diffusion of water molecules. The results also enable us to estimate the transformation rate at an arbitrary pressure and temperaturc. Then, we have estimated the transformation period of an air bubble into an air-hydrate crystal at a middle depth in the transition zone of the Vostok Station ice and we also discuss the formation of the transition zone.

\section{EXPERIMENTAL METHODS AND RESULTS}

Spccimens (about $20 \mathrm{~mm} \times 20 \mathrm{~mm} \times 5 \mathrm{~mm}$ ) were prepared from the Vostok Station ice core (1514m), which included secondary air bubbles. The bubbles were formed by the air-hydratc dissociation after ice recovery from the ice sheet, because no bubbles were observed in the fresh Vostok Station ice core deeper than $1250 \mathrm{~m}$ (Lipenkov, 1989). We expected that bubbles had maintained the structures of the clathrate hydrate and that they had had sufficient air molecules to be reconstructed under high hydrostatic pressures.

The experimental apparatus was the same as that of the previous study (Uchida and others, 1992). Experiments were conducted at temperatures $(T)$ that ranged from 254.7 to $269.7 \mathrm{~K}$ over pressures $(P$ ) ranging from 10 10 $20 \mathrm{MPa}$. The excess pressure, $P-P e$, ranged from about -1 to $8 \mathrm{MPa}$, where $P e$ was the dissociation pressure of the air-hydrate calculated by Miller (1969). Pressures were maintained within $\pm 1 \mathrm{MPa}$ during each experiment which continucd for more than 1 week.

The transformation from an air-bubble to an airhydrate crystal was observed only when $P$ was higher than $P e$, that is, $P-P e$ was positive. Figure 1 shows the typical transforming process of an air bubblc (opaque) into an air-hydrate (transparent). The experimental conditions were $T=269.9 \mathrm{~K}$ and $P=18 \mathrm{MPa}$. The rapid shrinkage of the bubble occurred just after pressurization (Fig. la and b), and it went on for a few hours. This rapid shrinkage was caused by the plastic dcformation of the surrounding ice driven by the difference between the bubble pressure and the applied one. Subsequently, the air-hydrate began to transform from the boundary between the ice and the bubble (Fig. 1c), and the boundary between air-hydrate and

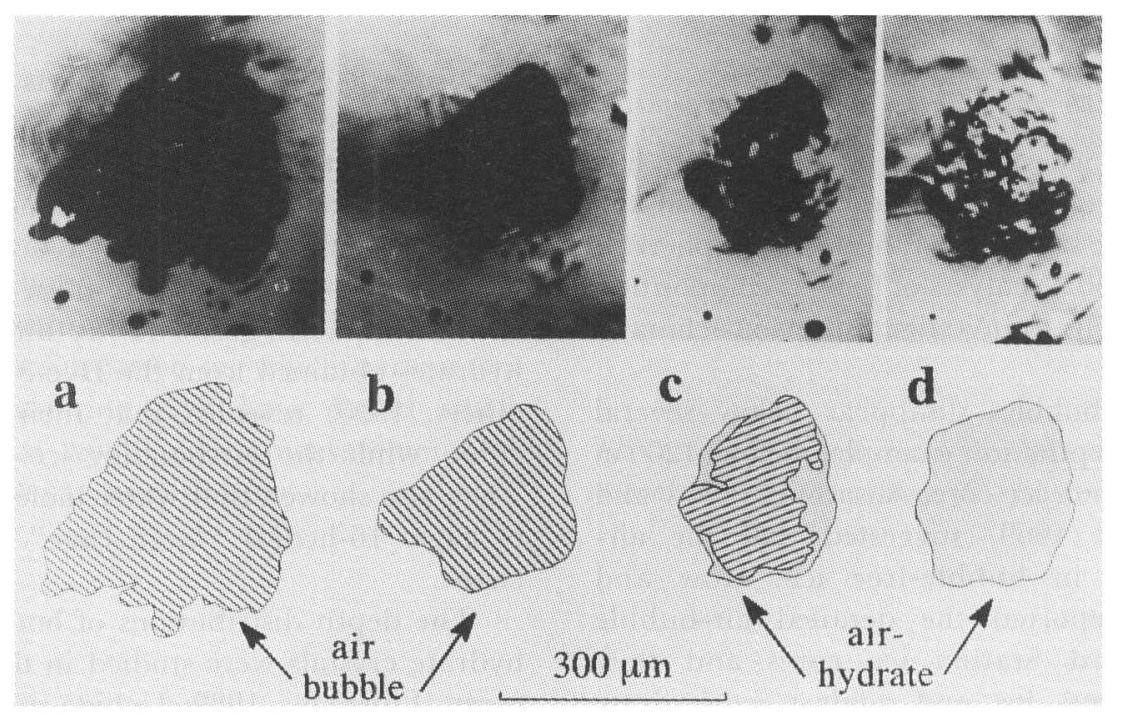

Fig. 1. Photographs and their illustrations of the transformation process of an air bubble inlo an air-hydrate at $269.9 \mathrm{~K}$ and $18 \mathrm{MPa}$. a. Before pressurization; bubbles were opaque; $b .1 \mathrm{~h}$ after pressurization; $c .78 \mathrm{~h}$, air-hydrate crystal (transparent) was growing; d. $164 \mathrm{~h}$, the bubble transformed into air-hydrale completely. 
bubble progressed toward the center of the air bubble. The transforming process took more than 1 week to complete (Fig. Id). We observed several air bubbles in the same specimen simultaneously and recorded the change of their outlines.

To estimate the transformation rate of the crystal, the cross-sectional areas of both the air-hydrate and air bubble were measured on each photograph. Then the radius of the sphere which had the same cross-sectional area of either air-hydrate or the sum of air-hydrate and bubble was calculated. The changes of the radii of airhydrate, $r$, and the sum of air-hydrate and air bubble, $R$, are illustrated in Figure 2. This figure shows that $R$ is almost constant during the transformation after the first rapid shrinkage of the air bubble. On the other hand, $r$ does not change at first for several hours, and then it increases almost linearly with time. The transforming rate of air-hydrate, $v_{t}$, was calculated from the slope of the line in Figure 2.

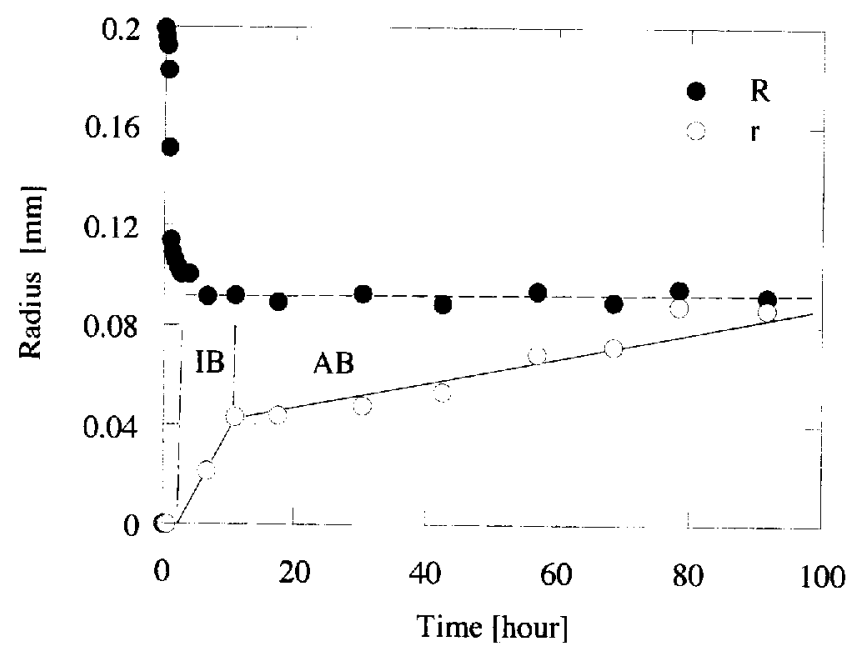

Fig. 2. The variations of radii $R$ and $r$ with time, where $R$ is the radius of the equivalent sphere of the sum of airhydrate and bubble, and $r$ is that of air-hydrate. At the time interval of $I B$, the transformation of air-hydrate progressed along the boundary between ice and the bubble. Subsequently, the boundary between the air-hydrate and the bubble grewe into the bubble at AB interval. The slopes of the lines represent the transforming rate of air-hydrate, $v_{\mathrm{t}}^{\mathrm{IB}}$ and $v_{\mathrm{t}}^{\mathrm{AB}}$, respectively.

We distinguish two intervals in the transformation period: the IB interval for the fast transformation period and the $\mathrm{AB}$ interval for the subsequent period. During the time interval of IB, the transformation of air-hydrate progressed along the boundary between ice and the bubble. Subsequently, at the $A B$ interval, the boundary between air-hydrate and the bubble grew into the air bubble. Figure 2 shows the transforming rate during the IB interval, $v_{t}{ }^{I B}$, is larger than that during the $A B$ interval, $v_{\mathrm{t}} \mathrm{AB}$.

Then we considered the pressure-dependence of $v_{t}$. As the experiments were carried oul at various temperatures, the excess pressure, $P-P e$, was used instead of the cxperimental pressure, $P$. Figure 3 illustrates the relationship between $v_{\mathrm{t}}^{\mathrm{AB}}$ and $P-P e$. The relationship between $v_{1}^{\mathrm{IB}}$ and $P-P e$ is almost the same figure as given in
Figure 3. We distinguish the data obtained from the experiments of different temperatures by the different symbols in this figure. Each data point is the mean value of $v_{t}{ }^{\mathrm{AB}}$ obtained in the same specimen. Error bars show the maximum difference between the mean value and each experimental value. This figure shows that $v_{\mathrm{t}}$ depends linearly on $P-P e$ and that $v_{\mathrm{t}}=0$ when $P=P e$. The dashed line at each temperature was calculated by fitting the data to the equation as follows:

$$
v_{\mathrm{t}}^{i}=K_{i}(P-P e)
$$

where $K_{i}$ is the reaction-rate constant at $i$ interval, and $i$ is either $\mathrm{IB}$ or $\mathrm{AB}$.

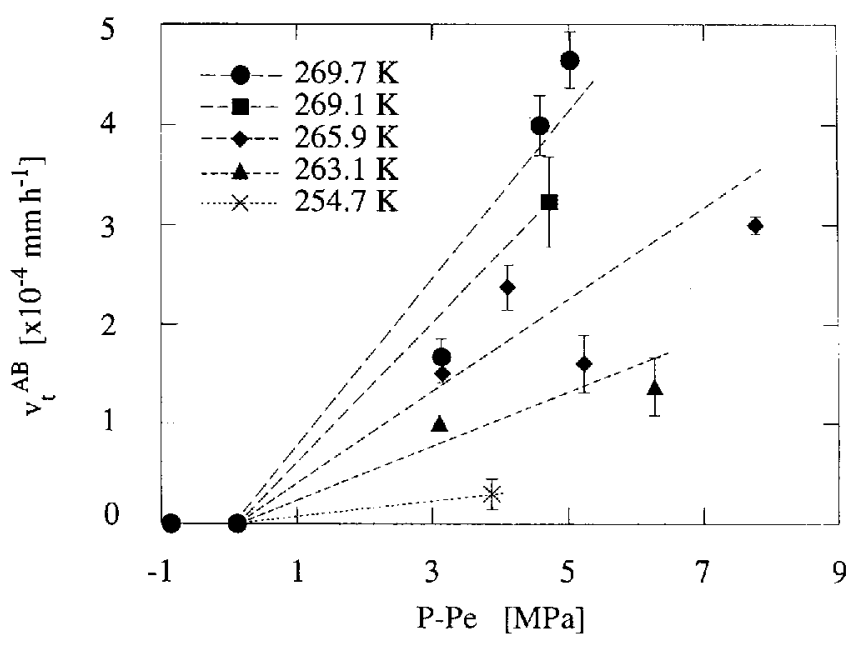

Fig. 3. Mean transforming rates of the air-hydrate $v_{t} \mathrm{AB}$ against excess pressure $P-P e$ at $269.7 K$ (denoted by the solid circles), $269.1 \mathrm{~K}$ (square), $265.9 \mathrm{~K}$ (diamond), $263.1 \mathrm{~K}$ (triangle) and $254.7 \mathrm{~K}$ (cross). Error bars show the mean standard devialions oblained by the calculation of $v_{\mathrm{t}}$.

The temperature-dependence of $K_{i}$ indicates that of the transformation rate. 'The $K_{i}$ calculated by Equation (1) are plotted in terms of the Arrhenius plot in Figure 4. The straight line in Figure 4 obtained by the least-squares method can be expressed by the following cquation:

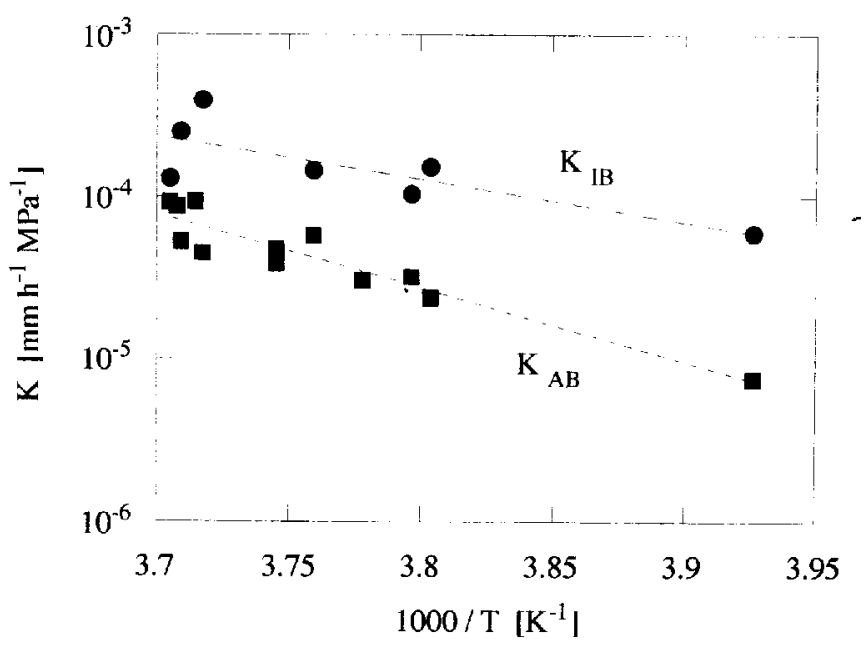

Fig. 4. Arrhenius plot of the reaction constants $K_{\mathrm{IB}}$ and $K_{\mathrm{AB}}$ for the crystal growth of air-hydrate. Each data point was calculated by Equation (1). 


$$
K_{i}=K_{0 i} \exp \left(-\frac{E_{i}}{k T}\right)
$$

where $K_{0 i}$ is a pre-exponential factor, $E_{i}$ is the activation energy for the reaction at $i$ intcrval and $k$ is the Boltzmann constant. The values of $K_{0 i}$ and $E_{i}$ obtained are as follows:

$$
\begin{aligned}
K_{0 \mathrm{AB}} & =1.1 \times 10^{6} \mathrm{~mm} \mathrm{~h}^{-1} \mathrm{MPa}^{-1}, E_{\mathrm{IB}}=0.52 \pm 0.17 \mathrm{eV} \\
K_{0 \mathrm{AB}} & =5.1 \times 10^{12} \mathrm{~mm} \mathrm{~h}^{-1} \mathrm{MPa}^{-1}, E_{\mathrm{AB}}=0.90 \pm 0.10 \mathrm{eV} .
\end{aligned}
$$

\section{DISCUSSION}

\section{The transformation process of air-hydrates from air bubbles}

Microscopic observations showed that an air bubble transforms to an air-hydrate crystal. Figure 3 shows that higher hydrostatic pressure than the dissociation one is necessary for the transformation process and that the transformation ratc $v_{\mathrm{t}}$ is proportional to the excess pressure $P-P e$. These results suggest that the driving force of the crystal growth of air-hydrates is $P-P e$.

The observations showed that the total radius $R$ did not change during the transformation from air bubbles to airhydrates. This result suggests that the air molecules included in the air bubble are sufficient to reconstruct the air-hydrate crystal. Water molecules in the bubble are, on the other hand, too small to reconstruct the air-hydrate crystal if the partial pressure of water vapor is equivalent to the equilibrium vapor pressure with ice. For the reconstruction it is necessary to supply water molecules from other places. The activiation energy for the transformation ratc at the $\mathrm{AB}$ interval, $E_{\mathrm{AB}}$, is about two times larger than $E_{\mathrm{IB}}$. This suggests that the kinetic process of the air-hydrate construction does not detcrminc the transformation rate. It is, therefore, considered that the rate-determining process of the transformation from air bubbles to air-hydrate crystals is mainly the additional process of supplying water molecules to the transformation sites.

This additional process of supplying water molecules to the transformation site at the IB interval is considered to be that the water molecules diffuse directly from the surrounding ice latticc. This is because the transformation site is the boundary between the ice and the bubble. The activation energy of the transformation during the IB period, $E_{\mathrm{IB}}$, is about $0.52 \mathrm{eV}$. This value is well in agreement with the activation energy of the self-interstitial of the icc, $E_{\mathrm{scl}}=0.56 \mathrm{cV}$ (Goto and others, 1986). The rate-determining process of the transform-ation during the IB interval is, therefore, considered to be the diffusion process of the self-interstitial in the ice latlice.

On the other hand, during the $\mathrm{AB}$ interval, the water molecules have to diffuse through the hydrate lattice to reach the transformation sites, or the boundary between the air-hydrate and the bubble. 'The larger valuc of $E_{\mathrm{AB}}$ than $E_{\mathrm{IB}}$ indicates that there are high energy barriers for the diffusion of water molecules through the hydrate lattice. Now we assumed that water moleculcs diffuse through the lattice of the air-hydrate. A water moleculc included in a cage can move to the next one only when the next cage includes no molecules. The cage occupancy of gas molecules in the air-hydrate crystal is about 0.8 (Hondoh and others, 1990), so the existence of gas molecules in cages may be an energy barricr for the diffusion of water molecules through the hydrate latice. Morcover, Hondoh and Lichida (1992) have pointed out that a water molecule included in a small cage cannot move without substitution by another water molecule constructing the hydrate lattice. This may also make the activation energy higher.

As for the value $P e$, we use the equation given by Miller (1969). Shoji and Langway (1987) have suggested that air-hydrates in some deep ice-core samples exist at a slightly greater depth than expected, which corresponds to the dissociation pressure of $\mathrm{N}_{2}$ hydrate. According to this, $\mathrm{Pe}$ should be the dissociation pressure of $\mathrm{N}_{2}$ hydrate. However, the difference between the dissociation pressures of air-hydrate and $\mathrm{N}_{2}$ hydrate is less than $0.65 \mathrm{MPa}$ in the present study. 'This value is smaller than the pressure variation during each experiment, $\pm 1 \mathrm{MPa}$. Therefore, we cannot determine whether $P E$ is cither the dissociation pressure of airhydrate or that of $\mathrm{N}_{2}$ hydrate.

\section{The transformation rate of air-hydrate crystals in the ice sheet}

Using Equations (1) and (2) for the $\mathrm{AB}$ interval, we can estimate the transformation rate of air-hydrate crystals in the ice shect at Vostok Station. At a depth of $900 \mathrm{~m}$, which is about the center of the transition zone, the temperature in the borehole was about $223.1 \mathrm{~K}$ (Ritz, 1989), and the hydrostatic pressure was about $7.8 \mathrm{MPa}$. The dissociation pressure of air-hydrate at this temperature is calculated as about $3.7 \mathrm{MPa}$; then the excess pressure $P-P e=4.1 \mathrm{MPa}$. The estimated transformation rate of an air-hydrate from an air bubble under these conditions is $v_{\mathrm{t}}(900 \mathrm{~m})=9.6 \times 10^{-8} \mathrm{~mm} \mathrm{~h}^{-1}$. The mean radius of an air bubble included in a $900 \mathrm{~m}$ ice core was measured as about $0.05 \mathrm{~mm}$ (Lipenkov, 1989). Then it takes about 60 years for the transformation of an air bubble into an air-hydrate crystal. This indicates that the transformation period from an air bubblc to an airhydrate crystal is sufficiently short compared with the period of the transition zone, about 60000 years (Lorius and others, 1985).

The transformation process of air-hydrate crystals in the ice sheet at Vostok Station may be illustrated as follows. At a depth of about $500 \mathrm{~m}$, the bubble pressure reaches the dissociation pressure of air-hydrate. An air bubble transforms into an air-hydrate soon after nucleation. Some bubbles transform into air-hydrate at the same depth, but others cannot transform because of the difficulty of nucleation of air-hydrate crysials at the boundary between the ice and the bubble. The difference of the transformation depth of each air bubble may form the transition zone.

'The transition zone can be attributed to the difficulty of the nucleation of the air-hydrate crystal. Figure 2 shows that the transformation from an air bubble into an air-hydrate requires several hours after rapid shrinkage of the bubble has been completed. This may indicate the difficulty of the nucleation of air-hydrate crystals even on 
to the bubble formed by the dissociation of the original air-hydrate. Shoji and Langway (1987) have proposed that the transformation process between air-hydrate and bubble is strongly controlled by the nucleation process. Recent experimental investigation (Ikcda and others, 1993) has shown that the nucleation of air-hydrate on an air bubble was sensitive to pressure.

\section{ACKNOWLEDGEMENTS}

The authors would like to acknowledge all Russian and French participants in the drilling, the field work and ice sampling of the Vostok ice core. We are grateful to the late Prolessor T. Kuroda and Dr.J. Ocampo for helpful discussions. Some of the cxperimental apparatus for this study was supported by Mitsubishi Heavy Industries, Lid. The present work was supported financially by the Asahi Glass Foundation and the Japancsc Science and Technology Agency.

\section{REFERENCES}

Goto, K., T. Hondoh and $\Lambda$. Higashi. 1986. Determination of diffusioncoeflicients of self-interstitials in inc with a now method of obscrving climb of dislocations by X-ray topography. Japanese 7. Appl. Phys, $253 i, 351-357$

Gow, A.J. and T'. W'illiamson. 1975. Gas inclusions in the Antarctic ice sheet and their glaciological significance. 7. Geophys. Res., 80 (36), $510 \mathrm{l}-5108$.

Gow, A.J., H.'T. Ueda and D. E. Garficld. 1968. Antarctic ice sheet; preliminary results of lirst core hole 10 bedrock. Science, $\mathbf{1 6 1}(3845$ ), 10111013.

Hondoh, 'I'. and T. Urhida. 1992. Formation process of clathrate airhydrate crystals in polar ice sheets. Low Temp. Sci., Ser. A, 51, 197-212. In Japanese.
Hondoh, T., H. Anzai, A. Goto, S. Mac, A. Higashi and C. C. Langway, Jr. 1990. 'The crystallographic structure of the natural air-hydrate in Greenland Dye-3 deep ice core. f. Inclusion Phenom. Molecul. Recognition Chem., 8/1 2, 1724.

Ikeda, 1'., I: Uchida and $\mathrm{S}$. Mar. 1993. The effect of hydrostatic pressure on the formation of air-hydrate crystals. Proc. NIPR Symp. Polar Meteorol. Glaciol., 7, 14-23.

Lipcnkov, V. Ya. 1989. Obrazovanie i razlojenie gidratov vozdukha v leduikovom ldu [Formation and decomposition of air hydrates in glacier ice]. Mater. Glyatsiol. Issled., 65, 58-64.

Lipenkov, V.Ya., A.N. Salamatin and Yu. A. Grigorveva. 1989. Matematicheskaja model; tchislennoe issledovanie processa uplotnenia lednikovogo lda [Mathematical model and numerical study of glacier-ice consolidation]. Mater. Glyatsiol. Issled., 65, 4958.

Lorius, C. and 6 others. 1985. A 150,000-yrar climatic record from Antarctic ice. Kature, 316 6029), 591-596.

Miller, S. L. 1969. Clathrate hydrates of air in Antarctic ice. Science, 165 , $489-490$.

Nakahara, J., Y. Shigesato, A. Higashi, T. Hondoh and C. C. Iangway, Jr. 1988. Raman-spectra of natural clathrates in deep ice cores. Philos. Mag., B57(3), 421-430.

Ritz, C. 1989. Interpretation of the temperature profile measured at Vostok, East Antarctica. Ann. Glaciol., 12, 138-144.

Shoji, II. and C. C. Langway, Jr. 1982. Air hydrate inclusions in fresh ice core. Vulwe, 298 5874$)$. 548-550.

Shoji, H. and C. C. Langway. Jr. 1987. Microscopic observations of the air hydrate bubble. Transformation process in glacier ice. 7 . Phys. (Paris), 48, Colloq. C1, 551-556. Supplement au 3.)

Cchida, T., T. Hondoh, S. Mae, P. Juval and V. Ya. Lipenkov. 1992 In-situ observations of growth process of clathrate air-hvdrates under hydrostatic pressure. In Maeno, N, and T. Hondoh, eds. Physics and chemisty of ice. Sapporo, Hokkaido University Press. 121-125.

Lchida, T., T. Hondoh, S. Mae, V. Ya. Lipenkor and P. Duval. 1994 Air-hydrate crystals in deep ice-corc samples from Vostok Station, Antarctica. J. Claciol., 40 (134), 79-86.

The accuracy of references in the text and in this list is the responsibility of the authors, to whom queries should be addressed. 